\title{
O IDOSO E A PRÁTICA DO LAZER EM ÁREAS NATURAIS E PROTEGIDAS
}

\author{
THE ELDERLY AND THE PRACTICE OF LEISURE IN NATURAL AND \\ PROTECTED AREAS
}

\author{
Daniel Righi Campos ${ }^{1 *}$, Patrícia Ortiz Monteiro ${ }^{2}$, Elisa Maria Andrade Brisola ${ }^{3}$ \\ 1 Mestrando do Programa de Mestrado em Desenvolvimento Humano pela Universidade de Taubaté, UNITAU - Taubaté, São Paulo, \\ Brasil, \\ 2 Doutora em Ciências Ambientais, Universidade de Taubaté-UNITAU, Taubaté, São Paulo, Brasil, patyortizmonteiro@terra.com.br \\ 3 Doutora em Serviço Social, Universidade de Taubaté - UNITAU, Centro Universitário do Sul de Minas - UNIS-MG, Varginha, MG, \\ Brasil, elisabrisola@uol.com.br
}

\section{Resumo}

Propõe-se uma reflexão acerca da prática do lazer pelos idosos em áreas naturais e protegidas, sua relação com o desenvolvimento humano, bem como, sua contribuição para a qualidade de vida no envelhecimento. Trata-se de uma análise bibliográfica, pautada nas literaturas que abordam o tema e que revelaram progressivo aumento da expectativa de vida, no Brasil, representando expressivo crescimento da população idosa. A pesquisa revelou que a prática do lazer tem importância significativa para a qualidade de vida e para o desenvolvimento humano. Percebeu-se, ainda, que existe uma busca crescente do idoso pela prática do lazer nas áreas naturais e protegidas, tais como os parques, o que propicia integração social e inúmeros benefícios para a qualidade de vida. Além desses benefícios, constata-se que, ao realizar atividades em áreas naturais e protegidas, é estabelecida uma relação de identificação do indivíduo com a natureza, o que contribui para sua sensibilização e para a adoção de atitudes de proteção e preservação ambiental.

Palavras-chave: Desenvolvimento Humano. Lazer. Idoso.

\begin{abstract}
A reflection on the practice of leisure by the elderly in natural and protected areas is proposed, its relationship with human development, as well as its contribution to the quality of life in aging. This is a bibliographical analysis, based on the literature that addresses the topic and which revealed a progressive increase in life expectancy in Brazil, representing a significant growth in the elderly population. The research revealed that the practice of leisure has a significant importance for the quality of life and for human development. It was also noticed that there is a growing search by the elderly for the practice of leisure in natural and protected areas, such as parks, which provides social integration and countless benefits for quality of life. In addition to these benefits, it appears that, when carrying out activities in natural and protected areas, a relationship of identification of the individual with nature is established, which contributes to their awareness and to the adoption of attitudes of environmental protection and preservation.
\end{abstract}

Keywords: Human development. Recreation. Elderly.

(C)UNIS-MG. All rights reserved. 


\section{INTRODUÇÃO}

Dados estatísticos baseados em censos demográficos indicam aumento do envelhecimento da população mundial. A Organização das Nações Unidas (ONU) revela que a população com 60 anos ou mais está aumentando cerca de $3 \%$ a cada ano, o que, globalmente, se apresenta como um aumento mais significativo quando comparada à taxa de crescimento populacional entre os grupos etários mais jovens (ONU, 2019).

Ainda segundo a ONU, em âmbito global, o número de pessoas com 60 anos de idade ou mais, deve saltar, de 962 milhões, em 2017, para 1,4 bilhão, em 2030, e 2,1 bilhões, em 2050. Ou seja, todas as regiões do mundo, exceto o continente africano, terão aproximadamente um quarto de suas populações compostas por pessoas idosas.

Tais previsões incidem diretamente nas questões voltadas ao desenvolvimento de um país, em que, ao contrário do que se vem disseminando, é preciso observar:

[...] o desenvolvimento exige outra lógica, que não a da produtividade a qualquer custo, competitividade e acumulação, encerra uma revolução de ideias e práticas sociais, que oriente pessoas e organizações para a produção e o consumo partilhado, respeitando os ciclos da natureza. Nesta perspectiva, praticamente inverte-se a ordem clássica, a economia colocando-se em função do desenvolvimento para que passe a estar centrado no ser humano, e não na acumulação do capital. (CORIOLANO, 2013, p. 129)

De acordo com Coriolano (2013), é notório que a relação entre o desenvolvimento e o crescimento econômico de um país coexistem, mesmo que, durante muito tempo, tenha sido considerado o crescimento econômico como sinônimo direto do próprio desenvolvimento. No entanto, há que esclarecer que esses conceitos se diferem e, que hoje, este é um consenso mundial, ainda que desenvolvimento e crescimento econômico guardem uma estreita relação entre si.

Apesar dos variados substantivos que acompanham o termo desenvolvimento, quando se fala em desenvolver economicamente um país, não significa pensar meramente na multiplicação de riquezas materiais, mas, sobretudo, na possibilidade de alcançar também desenvolvimento humano, social e ambiental (MEGUIS et al., 2015).

Com base nessa questão, busca-se compreender a importância do lazer para a qualidade de vida do idoso e sua relação com o desenvolvimento humano. Neste artigo, relata-se um estudo da prática do lazer em áreas naturais, compreendidas como unidades de conservação, como é o caso dos parques.

Para atender aos objetivos pretendidos com este artigo, foi utilizada uma abordagem exploratória, tendo como método de pesquisa o levantamento bibliográfico, a partir do entendimento de textos na interface entre os conceitos de lazer, idoso, desenvolvimento humano e lazer em áreas naturais (unidades de conservação).

Nas seções subsequentes, apresenta-se um paralelo entre o desenvolvimento humano e o idoso, para assim, relacionar as práticas do lazer em áreas naturais.

\section{O IDOSO E O DESENVOLVIMENTO HUMANO}

O envelhecimento populacional é um fenômeno mundial que teve início primeiramente nos países desenvolvidos, em decorrência da queda da mortalidade, das grandes conquistas do conhecimento médico, da urbanização planejada das cidades, da melhoria nutricional, da melhoria 
das condições socioeconômicas, da elevação dos níveis de higiene pessoal e ambiental, tanto em residências como no trabalho, e dos melhoramentos decorrentes dos avanços tecnológicos (CAMARANO, 2010). Em diversos países, a pirâmide demográfica vem se invertendo, fenômeno já observado em diversos pontos no continente europeu. Segundo o Instituto Brasileiro de Geografia e Estatística (2016; 2019), a taxa de crescimento da população de 60 anos ou mais é maior que para os outros grupos etários e estima-se que, em 2050, haveria 427 milhões de idosos nas regiões mais desenvolvidas do mundo e 1,7 bilhão nas regiões menos desenvolvidas.

Em uma perspectiva internacional, ao se analisar dados das projeções populacionais feitas pelas Nações Unidas (WORLD..., 2015), o crescimento esperado da proporção de pessoas de 60 anos ou mais de idade na população brasileira seria marcante nas próximas décadas. Entre 1950 e 2000 a proporção de idosos na população brasileira, que esteve abaixo de $10,0 \%$, foi semelhante à encontrada nos países menos desenvolvidos. A partir de 2010 , 0 indicador para o Brasil começa a se descolar destas regiões, aproximando-se do projetado em países desenvolvidos. Em 2070, a estimativa é que a proporção da população idosa brasileira (acima de 35,0\%) seria, inclusive, superior ao indicador para o conjunto dos países desenvolvidos (IBGE, 2016)

No Brasil, a evolução da composição populacional por grupos de idade aponta para a tendência de um envelhecimento demográfico, o que corresponde ao aumento da participação percentual dos idosos na população e à consequente diminuição dos demais grupos etários (IBGE, 2016). A proporção de adultos de 30 a 59 anos de idade teve um aumento no período compreendido entre 2005 e 2015, passando de 36,2\% para 41,0\%, assim como a participação dos idosos de 60 anos ou mais de idade, que aumentou de $9,8 \%$ para $14,3 \%$ no âmbito da população brasileira.

Com base nos dados do IBGE (2016; 2019), estima-se que o Brasil será, em 2025, o país com maior número de pessoas idosas da América Latina e o sexto em uma escala mundial. Confirmandose essa tendência, a quantidade de pessoas com 60 anos ou mais atingirá a marca de 40,5 milhões. Estima-se que o percentual de brasileiros com mais de 65 anos de idade até o ano de 2040 será de $17,41 \%$, enquanto em 2020 atingiu a marca de 9,83\%.

A expectativa de vida da população idosa, ou seja, das pessoas com mais de 65 anos, teve uma elevação de 8,2 anos, no decorrer do período compreendido entre os anos de 1940 e 2018 . "As expectativas de vida ao atingir 80 anos, em 2018, foram de 10,4 anos para mulheres e 8,6 para homens. Em 1940, esses valores eram de 4,5 anos para as mulheres e 4,0 anos para os homens" (IBGE, 2019). Tal fenômeno justifica-se a partir da melhoria das condições de saneamento básico da população e do acesso a vacinas, remédios e atendimentos de saúde.

Os dados revelam que as pessoas estão vivendo por mais tempo e a projeção é de que vivam cada vez mais. $O$ envelhecimento no Brasil vem, ao longo dos anos, promovendo muitos debates e redirecionando olhares. A reflexão perpassa temas como a qualidade de vida da pessoa idosa, as nuances da longevidade, as políticas públicas específicas para essa etapa da vida, reinserção social da pessoa idosa. Nesse imenso rol de considerações, incluem-se vertentes como saúde, lazer, segurança, sustento, acessibilidade, necessidades básicas e tantos outros assuntos implicados nessa temática.

Atualmente, uma das questões que mais impactam a qualidade de vida e o desenvolvimento humano do idoso é a aposentadoria. Apesar disso, devido às necessidades financeiras, muitos permanecem no mercado de trabalho (formal ou não) e reduzem o tempo livre, que seria ocupado com lazer. Isso afeta a qualidade de vida dessas pessoas no decorrer do processo de envelhecimento, comprometendo diretamente a questão do desenvolvimento humano. 
Fazito et al. (2017) destacam que compreender o conceito de desenvolvimento implica buscar relações de igualdade, voltadas à construção da felicidade, da qualidade de vida, do acesso às necessidades básicas, de direitos de acumulação e propriedade, de renda, etc. Isto posto, é importante destacar que a longevidade impacta no prolongamento do potencial produtivo dos trabalhadores mais velhos. Tanto em função do aumento da expectativa de vida, quanto em virtude do rápido desenvolvimento tecnológico, a população idosa vem se mantendo mais ativa na vida social e nas atividades profissionais, sejam essas remuneradas ou mesmo de caráter voluntário.

No entanto, especialmente nos países em desenvolvimento, essas pessoas - em geral expostas a algumas vulnerabilidades sociais e necessitadas de trabalho remunerado -, encontram poucas oportunidades de emprego em decorrência de um mercado de trabalho que oferece vagas restritas e limitadas, que muitas vezes excluem as pessoas idosas do processo de seleção.

As opções de trabalho disponíveis para os idosos, em sua maior parte, estão condicionadas às políticas e aos programas de aposentadoria. Em uma perspectiva global, os trabalhadores de países nos quais a cobertura de aposentadoria é reduzida tendem a permanecer no mercado de trabalho após os 65 anos, ao passo que os trabalhadores idosos dos países onde essa cobertura é elevada, tendem a aposentar-se mais cedo (PNUD, 2015). A discussão inerente a essa temática é bastante ampla e deve ser acolhida como fundamental para colaborar com reflexões que permeiem a elaboração de políticas públicas com foco nas especificidades desse público.

Segundo Poner (2012),

[...] nas últimas décadas, programas que propõem um envelhecimento saudável e ativo têm sido utilizados por inúmeras organizações governamentais e não governamentais, gerando diferentes repercussões na vivência do envelhecimento e na relação dos idosos com a sociedade. (PLONER, 2012, p. 3)

Com base nessas reflexões, é possível perceber que o desenvolvimento de um país não está atrelado unicamente às questões econômicas, ligadas ao trabalho. Isso porque o desenvolvimento humano engloba questões ainda mais complexas, relacionadas também a fatores psicossociais e ambientais. Portanto, a implantação de políticas públicas voltadas a garantir direitos sociais, como saúde, habitação, segurança e lazer, são fundamentais para o desenvolvimento integral do cidadão. No entanto, não basta criá-las, se não é dado ao idoso um amplo acesso a elas.

Nesse sentido, como ressalta Coriolano (2013), qualquer crescimento que não considere as necessidades das pessoas não pode ser considerado desenvolvimento de fato. Assim, um dos direitos sociais garantidos pela Constituição Federal, o lazer, muitas vezes é pouco debatido, visto que é frequentemente entendido como secundário para a saúde física e mental das pessoas.

Contudo, democratizar o lazer implica em democratizar os espaços (MARCELLINO, 1995). Ou seja, o desenvolvimento social e cultural que a atividade turística e o lazer podem proporcionar a seus praticantes e aos destinos turísticos, depende diretamente da oferta igualitária e democrática desses espaços e ambientes à toda a população, independente das diferenças individuais ou coletivas, como faixa etária.

Depreende-se disso que as ações voltadas à garantia dos espaços de lazer devem ser implementadas e revistas constantemente, com a finalidade de garantir que o direito ao lazer do idoso seja atendido em sua totalidade e efetividade, considerando-se as peculiaridades dessa parcela da população. 


\title{
3 O IDOSO E A PRÁTICA DO LAZER EM ÁREAS NATURAIS
}

A palavra lazer, apesar de ser tão amplamente utilizada, não tem um significado único. Pela sua etimologia, licēre (lazer) vem do Latim e quer dizer ser lícito, ser permitido, ter valor (HOUAISS, 2001). Muitos teóricos do assunto ainda não chegaram a um consenso sobre a extensão do significado do vocábulo, pois existem muitos entendimentos possíveis.

O campo do lazer, considerado como tempo livre, é fonte de discussões por inúmeros estudiosos do assunto. Diante deste fato, seguem, de forma breve, três ideias acerca do tema, conforme apresenta Fazito et al. (2017).

\begin{abstract}
Shaw e Williams (1994) resumem as discussões sobre a definição de lazer em três momentos: 1) lazer entendido como o tempo livre das obrigações, que é criticado por não diferenciar o tempo livre do trabalho do tempo livre para o lazer; 2) lazer definido como o tempo em que as atividades de lazer acontecem (HAWORTH, VEAL, 2005), que é criticado por assumir uma falsa objetividade, já que atividades como jardinagem e artesanato podem ser entendidas como lazer ou obrigação; e 3) lazer visto como uma atitude da mente (DE GRAZIA, 1973), a forma como as pessoas percebem as atividades que dão satisfação pessoal, mas que é criticado por ser impreciso, já que há fronteiras de escolhas individuais que são construídas socialmente, baseadas em posição social, expectativas e processo de socialização. (FAZITO et al., 2017, p.13)
\end{abstract}

No entanto, diante desses debates, utiliza-se aqui o conceito adotado por Dumazedier (1974), que compreende o lazer como

[...] um conjunto de ocupações às quais o indivíduo pode entregar-se de livre vontade, seja para repousar, seja para divertir-se, recrear-se e entreter-se, ou ainda, para desenvolver sua informação ou formação desinteressada, sua participação social voluntária ou sua livre capacidade criadora após livrar-se ou desembaraçar-se das obrigações profissionais, familiares e sociais. (DUMAZEDIER, 1974, p.34)

Em suma, o lazer acontece quando há tempo livre para a realização de atividades prazerosas. A prática do lazer e a experiência cultural e social que o turismo proporciona para os seus praticantes têm motivado cada vez mais as viagens e os deslocamentos para destinos que ofereçam atrativos voltados à prática do lazer, ao entretenimento, ao relaxamento e ao contato com a natureza. Como aponta Camargo (1998), atualmente se percebe que a sociedade tem prestado atenção ao lúdico e que o lazer passou a ser um item no conjunto das necessidades das civilizações e dos direitos dos indivíduos.

Até meados do século XX, a pessoa idosa não poderia desfrutar do lazer na companhia de amigos, ou viajar para se divertir com autonomia e independência. Necessariamente, seria apenas um coadjuvante em seu ambiente familiar e social. Na década de 1970 e no início dos anos 1980, por exemplo, era inimaginável um idoso praticar atividades físicas regulares, ou mesmo frequentar academias. Hoje, não é incomum encontrar idosos cheios de saúde e energia, mais independentes, mesmo que existam algumas limitações oriundas da idade.

Para Silva (2008),

Ao observar as manifestações culturais daqueles que envelhecem na contemporaneidade, identificamos mudanças significativas de hábitos, imagens, crenças e termos utilizados para caracterizar esse período da vida. Além das tradicionais representações que atrelam os momentos mais tardios da vida ao descanso, à quietude e à inatividade, surgem hábitos, imagens e práticas que associam o processo de envelhecimento a atividade, aprendizagem, 
flexibilidade, satisfação pessoal e vínculos amorosos e afetivos inéditos. (SILVA, 2008, p. 156)

Até meados do século XX, a pessoa idosa não poderia desfrutar do lazer na companhia de amigos, ou viajar para se divertir com autonomia e independência. Necessariamente, seria apenas um coadjuvante em seu ambiente familiar e social. Na década de 1970 e no início dos anos 1980, por exemplo, era inimaginável um idoso praticar atividades físicas regulares, ou mesmo frequentar academias. Hoje, não é incomum encontrar idosos cheios de saúde e energia, mais independentes, mesmo que existam algumas limitações oriundas da idade. Esse público necessita de um olhar mais atento por parte dos órgãos governamentais, pois as políticas públicas devem se atentar às peculiaridades dessa fase da vida, visto que o Brasil terá, em torno de uma década, uma população formada por mais de 40 milhões de pessoas acima de 60 anos.

A pessoas idosa pode apresentar características que, em geral, são associadas ao "ser jovem", se assim desejar e buscar alternativas para adequar seu corpo e suas experiências à passagem do tempo. Alguns idosos assumem responsabilidades com seus netos, outros ficam em uma condição de isolamento social, no ócio e no sedentarismo. O desejo de viver uma velhice com qualidade de vida vai além assunção de responsabilidades entre o conjunto de ocupações familiares, diante do cuidado com os netos e da realização de algumas tarefas domésticas.

Sob esse aspecto, Silva (2008) acrescenta que o espectro de descrições possíveis para o envelhecimento ampliou-se tanto que à "velhice", tal como a conhecemos, se somou à noção de "terceira idade", incorporando uma série de características inéditas.

O surgimento da categoria 'terceira idade' é considerado, pela literatura especializada, uma das maiores transformações por que passou a história da velhice. De fato, a modificação da sensibilidade investida sobre a velhice acabou gerando uma profunda inversão dos valores a ela atribuídos: antes entendida como decadência física e invalidez, momento de descanso e quietude no qual imperavam a solidão e o isolamento afetivo, passa a significar o momento do lazer, propício à realização pessoal que ficou incompleta na juventude, à criação de novos hábitos, hobbies e habilidades e ao cultivo de laços afetivos e amorosos alternativos à família. (Silva, 2008, p. 161)

A partir das últimas décadas, teve início um movimento de desconstrução do perfil de idoso como alguém de saúde frágil e dependente de familiares para realizar suas atividades sociais e de lazer. $\mathrm{O}$ antigo modelo, pautado nas imagens vovós que faziam crochês em suas cadeiras de balanço, já pode ser considerado antiquado. A pessoas idosa pode apresentar características que, em geral, são associadas ao "ser jovem", se assim desejar e buscar alternativas para adequar seu corpo e suas experiências à passagem do tempo. Alguns idosos assumem responsabilidades com seus netos, outros ficam em uma condição de isolamento social, no ócio e no sedentarismo. O desejo de viver uma velhice com qualidade de vida vai além assunção de responsabilidades entre o conjunto de ocupações familiares, diante do cuidado com os netos e da realização de algumas tarefas domésticas. Dessa forma, dialogando com esse novo perfil, os anseios e as vontades das pessoas idosas, principalmente na questão do lazer e de uma vida social ativa, são cada vez mais reivindicados e estão mais próximo de serem concretizados. Sair, divertir-se, encontrar amigos, viajar, ir ao parque, fazer atividades físicas, dançar e até voltar a estudar são desejos das pessoas que chegam à Terceira Idade, ou como muitas vezes a ela se referem, "Melhor Idade".

Nesse sentido, dialogando com esse novo perfil, os anseios e as vontades das pessoas idosas, principalmente em relação ao lazer e à uma vida social ativa, são cada vez mais reivindicados e estão mais próximos de serem concretizados. Sair, divertir-se, encontrar amigos, viajar, ir ao parque, fazer 
atividades físicas, dançar e até voltar a estudar são desejos das pessoas que chegam à Terceira Idade, ou como muitas vezes a ela se referem no senso comum, "Melhor Idade".

$\mathrm{Na}$ velhice, o lazer possibilita superar limitações e reconstruir a vida de forma positiva, criativa e autônoma. Atividades lúdicas, por exemplo, têm caráter socializante, pois possibilitam o desenvolvimento de hábitos saudáveis (VIANA, 1999). Essa possibilidade de reconstruir a vida, bem como o caráter socializante do lazer, favorecem a inclusão do idoso na sociedade.

Na cultura europeia, o idoso viaja mais a lazer do que os idosos de outros países. Entretanto, não se pode desconsiderar os fatores motivadores dessa característica, como a renda e a saúde, influenciadas por políticas públicas voltadas aos idosos. No Brasil, percebe-se crescente procura do idoso pelo lazer por meio da participação em grupos de convivência que são formados, muitas vezes, em associações, igrejas, clubes, bairros, etc. Uma das características marcantes dessa faixa etária, na prática do lazer, é a necessidade de integração e socialização com outras pessoas da mesma idade, ou com outros grupos que Ihes proporcionem uma vida social ativa e autônoma. Viajar para lazer é sinônimo de qualidade de vida entre os idosos, pois abre portas para o novo, para a vivência de novas emoções, para a aprendizagem, para o contato com diversas pessoas e com distintas culturas e além da apreciação de novas paisagens. Nos últimos anos, os idosos brasileiros descobriram esse novo caminho, seguindo a tendência precursora dos idosos europeus.

A procura pelo lazer longe dos centros urbanos e em áreas naturais ocorre com maior frequência, em todos os segmentos da sociedade, e com mais intensidade pelo público idoso. Há uma crescente conscientização da necessidade de vivências mais espontâneas e significativas, e surge a vontade de fuga da rotina estressante e do caos urbano (MARCELLINO, 1996). Entende-se também que as atividades de lazer em áreas naturais proporcionam melhor integração entre a necessidade de fuga, de quebra da rotina, e o prazer provenientes dos benefícios gerados a partir do lazer em contato com a natureza.

Quanto às áreas naturais,

[...] são consideradas como refúgio da vida silvestre, atraindo a curiosidade de muitas pessoas dispostas a conhecer espécies da flora e fauna ameaçadas de extinção. Diante disso, o Turismo tem sido uma atividade cada vez mais praticada nas áreas naturais, por agregar não somente o lazer e o entretenimento, mas também a sensibilização dos visitantes quanto ao uso sustentável e preservação dos recursos ambientais. (SCHERER et al., 2012, p. 2)

Nos últimos anos, constatou-se uma busca crescente acerca das práticas de lazer em áreas naturais, que passaram a representar um importante espaço para o desenvolvimento pessoal e social (MARCELLINO, 1990; 1995). A busca pelo lazer em contato com a natureza deve-se, principalmente, à busca pela qualidade de vida que favoreça o aumento da longevidade. Assim, entre os grupos sociais que demandam lazer em áreas naturais está o dos idosos.

Diferentes tipos de unidades de conservação, como é o caso dos parques, têm entre os seus objetivos o uso público de suas áreas para o lazer e a recreação, bem como a preservação do patrimônio biológico existente em sua área. De acordo com suas normas e finalidade, cada tipo de unidade de conservação apresenta permissão ou proibição do uso de suas áreas para visitação pública.

As unidades de conservação de Uso Sustentável têm como objetivo básico "compatibilizar a conservação da natureza com o uso sustentável de parcela dos seus recursos naturais" (COSTA, 2002, p. 32). Segundo delimita Costa (2002), são tipos de unidades de conservação de uso 
sustentável: Área de Proteção Ambiental, Área de Relevante Interesse Ecológico, Reserva da Fauna, Reserva de Desenvolvimento Sustentável e Reserva Particular do Patrimônio Natural.

Outro tipo de unidades de conservação são as de Proteção Integral, que têm como objetivo principal preservar o ecossistema e a biodiversidade. Nessas unidades é admitido exclusivamente o uso indireto dos seus recursos naturais em atividades como pesquisa científica e turismo ecológico (COSTA, 2002). São exemplos de unidades de conservação de Proteção Integral: Estação Ecológica, Reserva Biológica, Parque Nacional, Monumento Natural e Refúgio da Vida Silvestre.

Entre as categorias de unidades de conservação, os parques são as mais conhecidas em todo o mundo. Isso se deve, sobretudo, pela integração entre a preservação de seus recursos naturais com o uso público para fins não só recreativos, mas também educacionais e científicos. Costa (2002) esclarece que, no Brasil, os parques representam um grande atrativo turístico, sendo responsáveis pelo marketing do segmento do ecoturismo.

As normas e as restrições para a visitação pública nos parques são estabelecidas pelo seu Plano de Manejo, também denominado Plano de Gestão. Esse documento técnico se fundamenta nos objetivos gerais de uma unidade de conservação e orienta acerca das formas de uso de toda a área do parque, inclusive as áreas abertas ao público. Orienta também sobre manejo dos recursos naturais e sobre a implantação de estruturas físicas e de recursos humanos a serem empregados para o uso e a conservação da unidade natural.

As atividades de lazer em áreas naturais são um modo de conciliar diversão com preservação, na perspectiva da educação ambiental. Ou seja, ao mesmo tempo que entretêm o público, sensibiliza-o sobre a importância da proteção desses espaços. Nas práticas do lazer em áreas naturais, a relação com o meio ambiente permite que esses espaços sejam concebidos como locais de aprendizado. Estabelecem-se diversas formas de interação entre as pessoas e a natureza, inclusive para o público que necessita de adaptações estruturais para participação em atividades de lazer nesse ambiente (LIMA et al., 2018).

Nesse contexto, o turismo e o lazer realizados em ambientes naturais podem ser concebidos como atrativos que se distinguem daqueles realizados em ambientes que turistas e visitantes estão habituados a frequentar no meio urbano. Isso porque possibilita diferentes formas de lazer. As atividades em meio à natureza são uma possibilidade de vivência prazerosa e de crescimento pessoal. São práticas de lazer muito diferentes das experiências cotidianas nas cidades brasileiras, especialmente nos grandes centros, implementadas exclusivamente a partir da lógica de reprodução do capital e marcadas pelo crescimento desordenado, que não corresponde às necessidades reais da população (MARCELLINO, 1990; 1995).

Para Costa (2002), a oferta de uma infraestrutura mínima é condição fundamental para o atendimento às necessidades da demanda turística. Considerando que a visitação em áreas de uso público de parques se dá a partir de diferentes públicos, as suas trilhas devem estar aptas a atender às especificidades de grupos como crianças, pessoas com deficiência, pessoas com mobilidade reduzida, entre outras. É sobretudo diante desse cenário que surgem as discussões pertinentes à promoção de acessibilidade e inclusão nas áreas naturais.

\section{TURISMO E LAZER INCLUSIVO PARA O IDOSO}

Para que a atividade turística e o lazer sejam de fato democráticos e igualitários, a sociedade deve compreender sua importância e assumir a responsabilidade no fomento da acessibilidade e da 
inclusão para todos os segmentos sociais, em especial para os idosos e as pessoas com deficiência, ou ainda aquelas que apresentem qualquer modalidade de necessidade de atendimento especial.

A relação da pessoa idosa com as necessidades especiais vem do processo natural de envelhecimento. Muitas vezes, o idoso perde, de forma gradativa, o domínio dos seus principais sentidos, o que o insere no grupo de pessoas com necessidades especiais. Portanto, é bastante comum encontrar idosos saudáveis, mas já apresentando alguma dificuldade, limitação ou restrição quanto à mobilidade, à audição, à visão.

Sassaki (1997) afirma que, para se poderem incluir todas as pessoas, a sociedade deve ser modificada, deve assumir que ela é responsável por atender às necessidades de seus indivíduos, e acrescenta que a inclusão social depende do fato de que os sistemas de lazer e turismo estejam adequados a todas as necessidades individuais.

As áreas naturais e os espaços de lazer devem não só atrair o público idoso, mas também adequar-se às suas necessidades e condições, no sentido de promover a necessária acessibilidade para a sua inclusão na sociedade.

Conforme Sassaki (2003), hoje é ponto pacífico o direito das pessoas com deficiência às oportunidades de lazer, esporte e turismo como parte do seu desenvolvimento e bem-estar integral. No entanto, não mais separadamente da população geral. Priorizam-se hoje as atividades que reúnam pessoas com deficiências e pessoas sem deficiências no mesmo espaço de lazer e turismo. São as chamadas Atividades Integradas e Atividades Inclusivas.

As Atividades Integradas acontecem quando uma pessoa com deficiência consegue participar das atividades de lazer mesmo que não adaptadas. Já as Atividades Inclusivas ocorrem quando os programas de lazer são alterados para que as pessoas com deficiência possam participar integralmente com as demais pessoas.

No Brasil, já existem algumas cidades que oferecem roteiros e atrativos turísticos para esse tipo de público. No entanto, apenas um pouco mais da metade do mercado de parques e atrações turísticas informou ter realizado treinamento de pessoal no sentido de receber pessoas com deficiência e/ou mobilidade reduzida. Esses dados demonstram que existe ainda uma demanda de turismo no Brasil pouco trabalhada e que pode representar um grande potencial para o desenvolvimento da inclusão social. Estudar a acessibilidade significa optar por um caminho diferente na conquista de melhores condições de vida em sociedade (SIOTA et al., 2015).

Sendo assim, para que a acessibilidade ocorra de forma efetiva, algumas condições devem ser observadas. $O$ indivíduo precisa ter acesso à informação, deslocar-se e utilizar equipamentos com independência, interagir com os demais e participar de atividades, o que torna possível sua inclusão na sociedade (ELY; SILVA, 2009).

A prática do ecoturismo e de atividades de aventura tem recebido mais adesão pelo público idoso, que já encontra produtos e serviços adequados às suas necessidades específicas, o que lhes garante conforto e segurança na realização dessas atividades. Algumas unidades de conservação vêm desenvolvendo programas para o planejamento de trilhas acessíveis, tanto ao público idoso, quanto às pessoas com deficiência e restrição de mobilidade, assim como já ocorre no caso de praias com acessibilidade para cadeirantes. 


\section{CONSIDERAÇÕES FINAIS}

Os dados acerca do envelhecimento populacional no Brasil demonstram que em alguns anos $19 \%$ da população apresentará características etária acima de 60 anos. O perfil do idoso, na atualidade, em quase nada se assemelha ao perfil do idoso no passado. Hoje, pode-se dizer que os idosos são mais independentes e autônomos, quando se trata de suas realizações. A necessidade de se manter por mais tempo atuando no mercado de trabalho, se por um lado o mantém produtivo, por outro lado, implica, muitas vezes, menor disponibilidade de acesso e de tempo para a prática do lazer.

De modo geral, para o desenvolvimento humano, o lazer gera melhoria na qualidade de vida e conduz a uma participação social mais ativa. Daí a importância de serem instituídas políticas públicas voltadas para o idoso no que tange, não só às questões sociais, mas também ao lazer. Observa-se que a saúde e a mobilidade têm relevante impacto, tanto na quantidade quanto na qualidade do lazer desse grupo.

A prática do lazer, especialmente aquela que acontece em áreas naturais, oferece experiências prazerosas, educativas e sensibilizadoras, além de conectar as pessoas à natureza e propiciar bem-estar.

A crescente busca por prática do lazer em áreas naturais é percebida em todos os segmentos da sociedade, pois as pessoas anseiam por esse contato, para fugir da agitada vida dos centros urbanos. No entanto, quando se trata do público idoso, é preciso voltar o olhar para as questões de acessibilidade, de forma que esses espaços sejam adequados para seu atendimento integral e de forma inclusiva.

Os gestores das unidades de conservação, bem como os planos de manejo, que regem a gestão dessas áreas e estabelecem as diretrizes do uso público e da visitação, precisam dispensar maior atenção para as questões de acessibilidade desse público nos espaços de lazer e promover mais ações sociais nesse sentido.

Assim, o atendimento às necessidades dos idosos quanto à acessibilidade em espaços de lazer em áreas naturais, torna-se um elemento fundamental para que a inclusão de fato ocorra. $A$ eliminação de barreiras e a oferta de maior segurança e autonomia possibilitará que os idosos usufruam desse tipo de lazer tanto quanto os demais grupos.

\section{REFERÊNCIAS}

CAMARANO, Ana Amélia. Envelhecimento da população brasileira: uma contribuição demográfica. IPEA, Rio de Janeiro, 2010.

CAMARGO, L.O. de L. Educação para o lazer. São Paulo: Moderna, 1998.

CORIOLANO, L.N. Lazer e Turismo para o Desenvolvimento na Escala Humana. Revista Lusófona de Estudos Culturais. Vol. 1, n. 2, pp. 126-141, 2013.

COSTA, P. C. Unidades de Conservação: matéria-prima do ecoturismo. Série Turismo. São Paulo: Aleph, 2002

DUMAZEDIER, Jofre. Lazer e cultura popular - Debates. São Paulo: Perspectiva, 1976. 
ELY, V. H. M. B.; SILVA, C. S. Unidades habitacionais hoteleiras na Ilha de Santa Catarina: um estudo sobre acessibilidade espacial. Produção. v.19, n.3, p. 489-501, 2009. Disponível em: <http://www.scielo.br/pdf/prod/v19n3/07.pdf>. Acesso em: 20 jan. 2020.

FAZITO, M.; RODRIGUES, B.; NASCIMENTO, E.; PENA L.C.S. O papel do turismo no desenvolvimento humano. Paper do NAEA 372. Belém: UFPA, 2017. Disponível em:

https://periodicos.ufpa.br/index.php/pnaea/article/view/11075. Acesso em: 10 nov. 2021.

HAWORTH, J. T.; VEAL, A. J. (Eds.) Work and Leisure (New Ed). London: Routledge. 2005.

IBGE. Instituto Brasileiro de Geografia e Estatística. Em 2018, expectativa de vida era de 76,3

anos. Disponível em: https://agenciadenoticias.ibge.gov.br/agencia-sala-de-imprensa/2013agencia-de-noticias/releases/26104-em-2018-expectativa-de-vida-era-de-76-3-anos. Acesso em: 15 ago. 2020.

IBGE - Instituto Brasileiro de Geografia e Estatística. Síntese de indicadores sociais: uma análise das condições de vida da população brasileira: 2016 / IBGE, Coordenação de População e Indicadores Sociais. - Rio de Janeiro: IBGE, 2016.

LIMA, D. F.; LIMA, L. A.; MAZZARDO, O.; ANGUERA, M. G.; PIOVANI, V. G. S.; JUNIOR, A. P. S.; SILVA, M. P.; SAMPAIO, A. A. O padrão da atividade física no lazer de idosos brasileiros. 2018. Caderno de Educação Física e Esporte. Marechal Cândido Rondon, v. 16, n. 2, p. 39-49.

MARCELLINO, N. Estudos do Lazer: uma introdução. Campinas: Autores Associados, 1996.

MARCELLINO, N. Lazer e Humanização. Campinas: Papirus, 1995.

MARCELLINO, N. Lazer e Educação. Campinas: Papirus, 1990.

MEGUIS, T.; FARIAS, K.; VIANA, P.; HAMOY, Juliana. Do desenvolvimento global ao desenvolvimento local: novas perspectivas do desenvolvimento do turismo. 2015. Revista de Turismo Contemporâneo. Natal, v. 3, n. 1, p. 98-120, 2015.

ONU - ORGANIZAÇÃO DAS NAÇÕES UNIDAS. Envelhecimento. Disponível em: https://unric.org/pt/envelhecimento/\#: :text=Estima\%2Dse\%20que\%20o\%20n\%C3\%BAmero,1\%2 Omil\%20milh\%C3\%B5es\%20em\%202100.\&text=Em\%20todo\%20o\%20mundo\%2C\%20a,os\%20grup os\%20et\%C3\%A1rios\%20mais\%20jovens. Acesso em: 02 ago. 2020.

PARKER, Stanley. A sociologia do lazer. Tradução de Heloisa Toller Gomes. Rio de Janeiro: Zahar, 1978.

PNUD - PROGRAMA DAS NAÇÕES UNIDAS PARA O DESENVOLVIMENTO. Relatório do Desenvolvimento 2015. O Trabalho como motor do Desenvolvimento Humano. Disponível em: <https://www.br.undp.org/content/brazil/pt/home/library/idh/relatorios-de-desenvolvimentohumano/relatorio-do-desenvolvimento-humano-200014.html>. Acesso em: 29 jul. 2020. 
PLONER, Katia S. Educação para uma práxis solidária e um envelhecimento ativo. In: RUSCHMANN, Doris. V. D. M.; SOLHA, Karina. T. (org.). Turismo e lazer para pessoa idosa. Barueri, São Paulo: Manole Ltda, v. 1, 2012. p.3-24.

SASSAKI, Romeu. K. Inclusão no Lazer e Turismo em busca da qualidade de vida. São Paulo: Áurea, 2003.

SASSAKI, Romeu K. Inclusão: construindo uma sociedade para todos. 7. ed. Rio de Janeiro: WVA, 1997.

SCHERER, L.; PESSÔA, A.S.; LANZER, R. M. Turismo em Áreas Naturais: um Estudo de Caso no Município de Canela (RS). 2012. Anais do VII Seminário de Pesquisa em Turismo do Mercosul Turismo e Paisagem: relação complexa. Caxias do Sul, 2012.

SILVA, L. R. F. Da velhice à terceira idade: o percurso histórico das identidades atreladas ao processo de envelhecimento. História, Ciências, Saúde - Manguinhos. Rio de Janeiro, 2008. Disponível em:

https://www.scielo.br/j/hcsm/a/kM6LLdqGLtgqpggJT5hQRCy/?format=pdf\&lang=pt. Acesso em: 17 nov. 2021.

SIOTA, M. S.; ASHTON, M. S. G.; HEIDRICH, R. Turismo Inclusivo: as condições de acessibilidade em dois parques temáticos de Canela/RS, Brasil. 2015. Revista Contribuiciones a las Ciencias Sociales. Disponível em: https://www.eumed.net/rev/cccss/2015/04/turismo-inclusivo.html. Acesso em: 10 mai. 2020.

VIANA, M. Lazer e terceira idade: um lugar onde ninguém é velho. 1999. $131 \mathrm{f}$. Monografia (Especialização em Lazer) - Escola de Educação Física, Fisioterapia e Terapia Ocupacional, Universidade Federal de Minas Gerais. Belo Horizonte, 1999. 